\title{
Reverse Mortgages Payment Based on Type of House in Kuala Lumpur: Comparing HECM and MPRM
}

\author{
Suraya Fadilah RAMLI, Norkhairunnisa M REDZWAN, Farah Aisyah M HATTA, \\ Mohd Bokhari S ANUAR and Nazatul Nadhirah ZULKIFLI \\ Center of Actuarial Studies, Universiti Teknologi MARA (UiTM) \\ 40450 Shah Alam, Selangor Darul Ehsan, Malaysia \\ Corresponding author E-mail: surayaramli@tmsk.uitm.edu.my \\ Corresponding author E-mail: khairunnisa@tmsk.uitm.edu.my \\ Corresponding author E-mail: farasyah94@gmail.com \\ Corresponding author E-mail: mohdbokhari949@gmail.com \\ Corresponding author E-mail: nazadhira@gmail.com
}

\begin{abstract}
A reverse mortgages is a type of home loan for homeowners to receive an amount of money against the value of the house in the form of fixed monthly payments or a line of credit. It enables the elderly homeowners to access their home equity and hold up payment into cash of loan until a certain condition apply whereby the loan amount will not exceed the home value over the life of the loan. This study aims to compare reverse mortgages payment between the Home Equity Conversion Mortgages (HECM) model by United State and Malaysian Proposed Reverse Mortgages (MPRM) loan structure on every type of house in Kuala Lumpur. Both loan structures have slight difference in the loan amount. From gender perspectives, it shows that male received higher amount of payment received compared to female. This situation happens because the difference in the life expectancy where one of the elements of reverse mortgages payment, whereby female are longer live than male due to mortality perils. Thus, between two models, the model that gives more payment towards Malaysia elderly is HECM rather than MPRM.
\end{abstract}

Keywords: Reverse mortgages; loan; HECM; MPRM; Kuala Lumpur

\section{Introduction}

A mortgage is a debt application to buy authentic estate and it is used by purchaser of property to access funds. The borrower is obligated to pay back pre-planned set of payment. One the other hand, reverse mortgage enables elderly to access the home equity they built up in their homes now and hold up payment into cash of loan until they die, move out or sell their home. This product is designed for elderly in range of age starting 62 and above. It is a type of home loan that used to receive the money of your house. It gives them the privilege to take their home equity without sales their own house. The borrower should own their property and it must be their main residence. Reverse mortgages is intended for the elderly to create income by permitting them to unlock the illiquid assets which have attached in their housing equity.

Besides, there is no monthly mortgage payment require however the interest is added up to the loan balance for each month. In time, it will decrease house value or the borrower continues to live in the home for many years when the rising loan balance. The demand of reverse mortgage has been inclining because it turns out to be a quick alternative for households with low income, modest wealth, and poor health, especially retirees who needed extra income or paying for long term care.

There is a lot to consider before signing up for reverse mortgage. Based on the study conducted by Shao, Hanewald and Sherris
[16], their findings suggest that risk factors associated with a property's characteristics should be used in the pricing and risk analysis of reverse mortgages loans. According to Bishop and Shan [2], there are a number of downsides from the demand aspect as reverse mortgage decrease the quantity of assets for homeowners.

In a study conducted by Acciai and Firebaugh [1] they make comparisons of the decline of life expectancy between male and female. Their results indicate that male's decline in life expectancy was mainly because accidental poisoning or homicide while female's decline in life expectancy is because of heart disease and mental illness. However, Chio et al. [5] found that life expectancy of elderly in depends on depression level where non-depressed elderly. It means that when not depressed or they are happy, their life expectancy tends to increase. Linden and Ray [10] found that private and public health expenditures had similar positive effects on life expectancy. Guedes et al. [9] stated that cancer patients increase their life expectancy as they achieve happiness and mental health. According to Department of Statistic of Malaysia (DOSM) [6], the average remaining age in years for an individual is expected to live at the beginning of the certain age is the meaning of life expectancy. The life expectancy is increasing; it is known that pensioners in Malaysia have live longer than expected. Meanwhile in a study conducted by Fotourehchi [8], found that the air consumes will become more polluted and this will lead to decreasing in life expectancy since percentage of population that live in urban areas increasing and getting crowded. 
Study done by Shamshimah and Noriszura [12] shows that the Malaysian population especially the working men are more likely to become disabled or die than women employees hence reverse mortgages is an alternative for them to prepare for their after retirement in the future. While Syazreen, Purcal and Parr [15] found that based on coherent among Malays, Chinese and Indians in Malaysia, Chinese has lower mortality rates.

Thus, Syazreen et al [13] concluded that different mortality rate among races in Malaysia will overall help to improve the mortality rate of Malaysians itself. With better mortality rate, retirees should prepare to sustain the lived after retirement. Reverse mortgages is widely known, but in Malaysia it is still a new financial product that should be developed to help retirees generate more funds to sustain their living

\section{Research Method}

This research focused on finding the price of loan amount that will be received by the elderly based on each type of house in Malaysia and comparing the amount of loan will be received using two different formulas to see which one suit for elderly in Malaysia Thus, this study will apply House Equity Conversion Mortgages (HECM) and the Malaysian Proposed Reverse Mortgages (MPRM) based on the study conducted by Redzwan at al. [11] and others in order to fulfil the objectives of the research. According to Shan [2] it is secured by the borrower's home equity. Since HECM loan is a superior reverse mortgages product in U.S. hence the loan is issued by private banks and insured by the Federal Housing Administration (FHA). Although HECM still follows the reverse mortgages homeowners which known as the current reverse mortgages product even though HECM has a different name. Meanwhile, MPRM is a loan structure uses the forecasted value of interest rate and the growth of the future house price, the incurred loan cost and prediction on loan termination from the actuarial structure based on the formula from the HECM and Korean Reverse Mortgages (KRM).

Several sources have been used to search for type of house in Malaysia and reverse mortgages articles. The types of house in Malaysia are bungalow, semi-detached, double-story, single-story, condominium, and apartment and others while the keywords used are reverse mortgages pricing, housing, loan balance and mortgages insurance premium, HECM and Net Single Premium (NSP). Several assumptions have been made which are:

1. Interest rate is constant throughout the year which is 3 percent according to Central Bank Malaysia

2. Loan amount will be received monthly

3. The growth of house price is constant

4. The borrower's age started from 60 until 80 .

\subsection{Source of Data}

The type of data for this research is secondary data which was taken from National Property Information Centre (NAPIC) and Central Bank Malaysia (BNM). Current house prices, average growth rate of housing price and average house price in Kuala Lumpur was obtained from NAPIC. This data will be used to find the pricing for HECM and proposed pricing in Malaysia and while from BNM mortality table and market interest rate will be used to find mortgages premium insurance that are proposed by Redzwan at al. [11] and find the pricing as well. Age, gender and base lending rate also will be used to complete this research.

\subsection{Methods of Analysis}

A reverse mortgage protected by the borrower's home equity is how HECM is being defined. Over time, the borrower's home equity rises over time and the mortgages debt declines are how the forward mortgages works while reverse mortgages are the vice versa of forward mortgage by Bishop and Shan [3]. HECM is the way to find loan amount. In the U.S. HECM program, as an upfront mortgages insurance premium (UP0), as well as a monthly mortgages insurance premium (MIP), according to the annual rate of 0.5 per cent of the outstanding loan balances. The loan amount of HECM that borrower will receive is determined by the principal limit. Furthermore, the lenders could use the formula to find the constant monthly reverse mortgages payment and the lump sum reverse mortgages payment as well based on the HECM reverse mortgages method.

According to the Fontinelle [7], subsequent to accounting for the loan's closing costs, net principle limit is the sum of money a purchaser of reverse mortgages can receive from the loan once it closes. It accordingly on the amount of borrower has to pay in origination fees, mortgages insurance and other closing costs and depends on the primary principal limit, which depends on age of the borrower at application time, the loan's interest rate and the home's appraised price. In the study conducted by Chena, Cox and Wang [4], under HECM, the interest rate might be either flat or flexible charged on the loan might with annual or monthly adjustments related to the one-year Treasury bill rate. Ninety-nine percent had a changeable interest rate of the HECM loans issued to date. HECM loans do not necessitate any refund until a borrower sells the property, moves out, or dies to avoid unintentional dislocation of old homeowners. A borrower also has the alternative of prepaying the outstanding loan balance devoid of consequences. As soon as a borrower discontinues paying monthly property taxes and insurance or fails to sustain the property up to a least maintenance level, a foreclosure is able to take place. Chena, Cox, and Wang [4]. US Department of Housing and Urban Development (HUD) introduced the new Principal Limit Factor (PLFs) table which result in approximately 15 percent decline in principle limits for most borrowers. In addition to adding non-borrowing spouses, the PLFs table increased the amount of earnings obtainable for older borrowers in low-rate environments, while plummeting PLFs for the most HECMs set higher interest rates. PLFs of reverse mortgage increase with age until age 90; it means no increases in the PLF after such age.

Thus

$\frac{\text { Net Principle Unit }}{\frac{1-(1+\text { Monthly Compounding Rate })^{-k}}{\text { Monthly Compounding Rate }}}$

Where,

Net Principle Limit (NPL):(PLFs $\times$ Avg House Price) -MIPClosing Cost

Principle Limit Factor: NPL \%×Max. Claim Amount

Closing Cost $\quad: 1.5 \% \times$ Initial House Price

Monthly Compounding Rate: $\frac{\text { Expected Rate i - Periodic }}{12}$

Periodic: $\frac{\text { Annual Interest Rate }}{12}$

K: (Maximum Age - Borrower's Age $) \times 12$ 


$$
L S U M^{H E C M}=P M T_{C}^{H E C M} \times \frac{(1+\text { Monthly Compounding Rate })^{k}-1}{\text { Monthly Compounding Rate }}
$$

For Malaysian Proposed Reverse Mortgages (MPRM) developed by Norkhairunnisa and others (2016) is based on the forecasted value of interest rate and the growth of the future house, the incurred loan cost and prediction on loan termination. The Mortgages Insurance Premium (MIP) is the instrument used to cover all losses when crossover risk occurs including the house appreciation values.

$$
L A(1+i)^{n}=H_{0}(1+g)^{n}
$$

Whereby,

$\begin{array}{ll}L A & : \text { Net Principle Amount + Insurance } \\ H_{0} & : \text { House Price at Time } 0 \\ g & : \text { Growth House Price }\end{array}$

The MIP is charged based on Insurance Net Single Premium (NSP) and NSP is defined as the present value of the future death benefit. Net single premium is assumed to be insured by the lenders to be charged to borrowers as the reverse mortgages premium.

$$
\begin{aligned}
& N S P=A_{x: n}^{1} \\
& A_{x: n}^{1}=\sum_{k=0}^{n m-1} v^{(k+1) m} \quad{ }_{k / m} \mathrm{p}_{x} \quad{ }_{1 / m} \mathrm{q}_{(x+k) / m}
\end{aligned}
$$

Whereby,

$$
\begin{aligned}
& \mathrm{k} \text { : The multiple of } 1 / \mathrm{m} \text { beginning }[\mathrm{k} / \mathrm{m},(\mathrm{k}+1) / \mathrm{m})] \text { within which } \\
& \text { the policy age } \mathrm{T}-\mathrm{x} \text { at death is to lie } \\
& \mathrm{n} \text { : Number of years } \\
& \mathrm{m} \text { : Mode of payment } \\
& \mathrm{x} \text { : Borrower's age }
\end{aligned}
$$

\subsection{Comparison between Hecm and Mprm Based on Type of House}

Assume the age of the borrowers started from 60 to 80 but the loan amount that will be received will vary each year according to their differences in life expectancy by gender and is due to the eligibility of the HECM program on the age of the borrowers as of the data retrieved from DOSM while the vary of life expectancy on gender will be taking care of as they are differed on male and female. The type of house in Malaysia, same goes to other countries, which are terraced, semi-detached, detached and high-rise unit house, leads to a different house price whereby the growth rate of the houses will be different from each other. Lastly, comparing the loan amounts received according to the house located in each Kuala Lumpur's region which divided to central, north and south. The market demands of housing in Malaysia mainly in Kuala Lumpur are differing on each region. The prices and the growth rate of the house will be in the regions of Kuala Lumpur's rates.

\section{Results and Analysis}

From the collected data and observation, this study:

(1) Estimates the reverse mortgages pricing between HECM and MPRM based on the type of house in Kuala Lumpur. Age range of 60 until 80 years old is calculated from year 2014 to 2017 which to recognize the trend in the payment. Thus, for the first objective, we estimate the reverse mortgages pricing model between HECM and MPRM based on the type of house. The calculation has been made for each gender, age between 60 until 80 and type of house.

(2) Determine which reverse mortgages pricing model are more profitable for Malaysia based on the age, gender and type of house between HECM and MPRM. From the result, HECM loan payment is lower than the MPRM loan payment at the early age, 60. It gets higher than the MPRM at age 65 to 80 . Both HECM and MPRM loan payment increases consistently for male but as for female, the payment for HECM and MPRM results differently. Female payment for HECM is not consistently increasing at early age 60 to 69 which the payment is decreasing. This is because the life expectancy for female is depending on age whereby every 4 years the age goes up and down. Therefore, at the age of 70 to 74, the HECM payment for female is lower than MPRM loan payment.

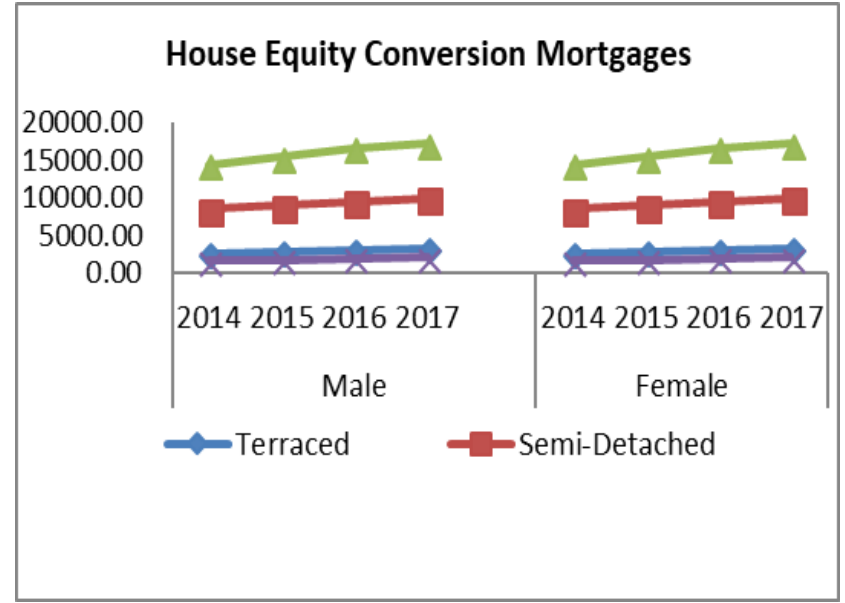

Fig. 1: Average HECM Payment by Type of House and Gender

Figure 1 shows the average HECM payment by the type of house for gender in Kuala Lumpur. This is an identifying which make higher payments between male and female. For both genders, detached house has the highest payment while high-rise unit house has the lowest payments. This relates to the different prices of the type of house in Kuala Lumpur where detached house is the most expensive house in Malaysia.

Furthermore, HECM payment for male is higher compared to female because male has shorter life expectancy than female. Therefore, male homeowners with detached house are obligated for a higher HECM loan payment compared to other type of house in Kuala Lumpur while for female homeowners will have slightly lower HECM loan payment with detached house.

Figure 2 shows the average MPRM payment by the type of house for gender in Kuala Lumpur. This is an identifying which make higher payments between male and female. It is shown that the payments for detached house have the highest followed by semidetached, terrace and high-rise unit for both genders. This relates to the different prices of the type of house in Kuala Lumpur where detached house is the most expensive house in Malaysia. Furthermore, male resulted in higher HECM payment as male has shorter life expectancy rather than female. Therefore, male homeowners with detached house will have a higher HECM loan payment compared to other type of house in Kuala Lumpur while for female homeowners will have slightly lower HECM loan payment with detached house. 


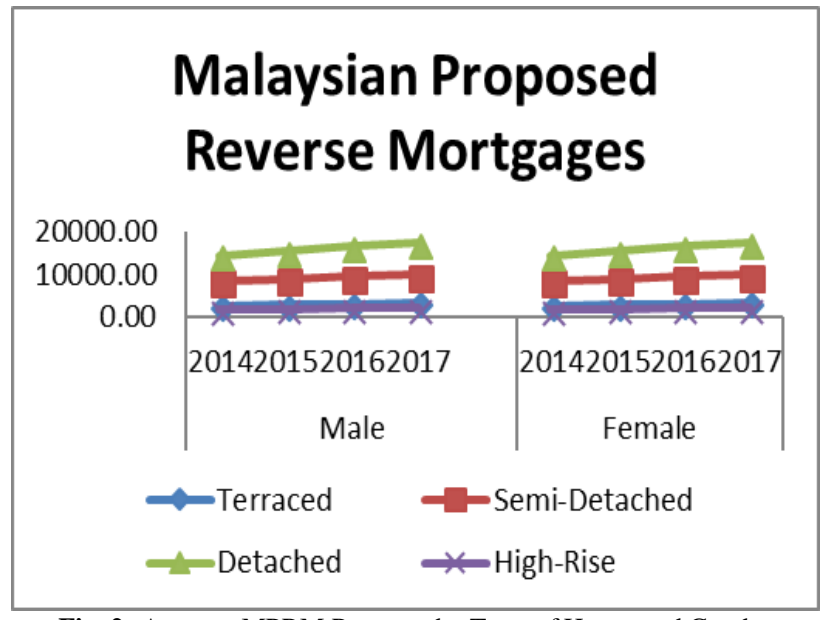

Fig. 2: Average MPRM Payment by Type of House and Gender

In a nutshell, both HECM and MPRM results in different payments for both gender. Relatively, male homeowners will gain a higher reverse mortgage loan payment compared to female homeowners as the life expectancy for male is shorter than female. Meanwhile, we analyzed that HECM loan payment is lower than the MPRM loan payment at the early age 60 . It gets higher than the MPRM at age 65 to 80. Both HECM and MPRM loan payment increase consistently for male but as for female, the payment for HECM is not consistently increasing at early age 60 to 69 which the payment is decreasing. This is because the life expectancy for female is dependable on age whereby every 4 years the age goes up and down. Therefore, at the age of 70 to 74 , the HECM payment for female is lower than MPRM loan payment

\section{Conclusion}

Based on this study, both HECM and MPRM loan structures have slightly different in terms of loan amount. From gender perspectives, those who have lower life expectancy will receive higher payment and vice versa. Furthermore, comparison had been made based on type of house which are terrace, semi-detached, high-rise unit and detached. It can be concluded that the higher the value of the house, the higher the payment received. The more payment received by elderly in Malaysia will determine the best model between Malaysia proposed loan structure and HECM. Thus, between two models, the model that gives more payment towards Malaysia elderly is HECM rather than MPRM. Thus, Malaysia should produce its own principal limit table to better understand and assist retirees to produce more income after retirement. The comparison of loan structure between proposed loan structure and HECM of the reverse mortgage can be a guide to government when they want to implement reverse mortgage in Malaysia. Government can decide which loan structure is the best for Malaysian elderly whether proposed loan structure of Malaysia or HECM so that they can reduce the problem or risk occurs when they implement the reverse mortgage.

The risk potential in this product should also be highly considered so it benefits both lenders and borrowers. Approaches such as Value-At-Risk (VaR) and Monte Carlo Simulations done in Siti et al [17] should be conducted to determine the performance of various industry, in this case is reverse mortgage. Apart from that, to ideally include gender and age factors in the new principal limit factor, Syazreen, Akmal and Nordin [14] recommends the Lee Carter model to forecast mortality more accurately.

\section{Acknowledgement}

This research is supported by Universiti Teknologi MARA and a grant from Ministry of Higher Education Malaysia. (Research Project No: 600-RMI/RAGS 5/3 (50/2015)

\section{References}

[1] Acciai F \& Firebaugh G, "Why did life expectancy decline in the United States in 2015? A gender-specific analysis", Social Science \& Medicine, Vol. 190, (2017), pp. 174-180

[2] Bishop TB \& Shan H, "Reverse Mortgages: A Closer Look at HECM Loans", NBER Papers on Retirement Research Centre Project, (2008), pp. 1-51.

[3] Bunnell T, Barter PA \& Morshidi S, "Kuala Lumpur metropolitan area: A globalizing city-region”, Cities, Vol. 19, No. 5, (2002), pp. 357-370.

[4] Chen H, Cox SH \& Wang SS, "Is the Home Equity Conversion Mortgage in the United States sustainable? Evidence from pricing mortgage insurance premiums and non-recourse provisions using the conditional Esscher transform", Insurance: Mathematics and Economics, Vol. 46, No.2, (2010), pp. 371-384.

[5] Chiao CY, Lee SH, Liao WC, Yen CH, Lin YJ, Li CR, Lai TJ, Lin HS, Lee MS \& Lee MC, "Social Participation and Life Expectancy - The Case of Older Adults in Taiwan from 1996 to 2003", International Journal of Gerontology, Vol. 7, No. 2, (2013), pp. 97-101

[6] Department of Statistics Malaysia Official Portal. https://www.dosm.gov.my/v1/index.php. Accessed January 27, 2018.

[7] Fontinelle A. Reverse Mortgages Net Principle Limit. https://www.investopedia.com/term/r/reverse-mortgages-netprincipal-limit.asp. Accessed January 27, 2018.

[8] Fotourehchi Z, "Health effects of air pollution: An empirical analysis for developing countries", Atmospheric Pollution Research, Vol. 7, No. 1, (2016), pp. 201-206.

[9] Guedes R, Meta-Oliveira M, Pereira E, Peixoto MJ, Ferraz I, Oliveira M \& Silveira C, "Mental health of college students: Fiveyear experience of the university psychiatric outpatient clinic of São João hospital centre", European Psychiatry, Vol. 41, (2017), pp. s608.

[10] Linden M \& Ray D, "Life expectancy effects of public and private health expenditures in OECD countries 1970-2012: Panel time series approach", Economic Analysis and Policy, Vol. 56, (2017), pp. 101-113.

[11] Mohamed Redzwan N, Ramli SF, Mohamad AI, Mohd Amin MN \& Syed Mohamed Shahruddin SNS, "A new loan structure for elderly: Adopting reverse mortgage plan in Malaysia", International Academic Research Journal of Business and Technology, Vol. 2, No. 2, (2016), pp. 179-183.

[12] Samsuddin S \& Ismail N, "Transition probabilities of health states for workers in Malaysia using a Markov chain model", AIP Conference Proceedings, Vol. 1830, No. 1, (2017), pp. 040002.

[13] Shair SN, Ishak SA, Yusof AY \& Murad A, "Forecasting agespecific mortality rates and life expectancy at births for Malaysian sub-populations", World Academy of Science, Engineering and Technology, International Journal of Economics and Management Engineering, Vol. 4, No. 2, (2017),

[14] Shair S, Akmal F \& Nordin N, "A multi-developing-country comparison of the Lee-Carter model for mortality and life expectancy projections", Journal of Fundamental and Applied Sciences, Vol. 9, No. 6S, (2017), pp. 371-383.

[15] Shair S, Purcal S \& Parr N, "Evaluating extensions to coherent mortality forecasting models", Risks, Vol. 5, No. 1, (2017), pp. 120.

[16] Shao AW, Hanewald K \& Sherris M, "Reverse mortgage pricing and risk analysis allowing for idiosyncratic house price risk and longevity risk", Insurance: Mathematics and Economics, Vol. 63, (2015), pp. 76-90.

[17] Abd. Gani SM, Mohd MA, Shima SN \& Kamarul Adzhar ZAABSL, "Value-at-risk on different economics sectors in Malaysia", Journal of Engineering and Applied Sciences, Vol. 12, No. 9, (2017), pp. 2289-2293. 